\title{
Field Trial of a Thermostable Peste des petits ruminants (PPR) Vaccine in a Semi-Arid Zone of Nigeria
}

\author{
Abdul-Dahiru El-Yuguda ${ }^{1 *}$, Saka Saheed Baba ${ }^{1}$, Abdul Ganiyu Ambali ${ }^{2}$, Gordon Onyebuchi Egwu ${ }^{3}$ \\ ${ }^{1}$ Animal Virus Research Laboratory, Department of Veterinary Microbiology and Parasitology, Faculty of Veterinary Medicine, \\ University of Maiduguri, Maiduguri, Nigeria; ${ }^{2}$ Department of Veterinary Medicine, Faculty of Veterinary Medicine, University of \\ Ilorin, Ilorin, Nigeria; ${ }^{3}$ Department of Veterinary Medicine, Faculty of Veterinary Medicine, University of Maiduguri, Maiduguri, \\ Nigeria. \\ Email: ${ }^{*}$ abduldahiru@gmail.com
}

Received November $28^{\text {th }}$, 2013; revised December 27 ${ }^{\text {th }}$, 2013; accepted January $3^{\text {rd }}, 2014$

Copyright (c) 2014 Abdul-Dahiru El-Yuguda et al. This is an open access article distributed under the Creative Commons Attribution License, which permits unrestricted use, distribution, and reproduction in any medium, provided the original work is properly cited. In accordance of the Creative Commons Attribution License all Copyrights (C) 2014 are reserved for SCIRP and the owner of the intellectual property Abdul-Dahiru El-Yuguda et al. All Copyright (C) 2014 are guarded by law and by SCIRP as a guardian.

\section{ABSTRACT}

The field trial of a candidate thermostable Peste des petits ruminants (PPR) vaccine was carried out in flocks of sheep and goats under the extensive system of management. The immune response of vaccinated animals was determined using the neutralisation test to detect PPR virus specific antibody. Vaccinated animals seroconverted and a four-fold or more rise in antibody titre were observed between pre-vaccination and post-vaccination antibodies. The vaccine elicited significant antibody response in goats through the different routes of administration (intramuscular, intranasal, intraocular, subcutaneous and orally), but was poorly transmitted between the vaccinees and in-contact animals. The sheep responded poorly to the vaccine administered through most of the routes, except for those vaccinated through intramuscular and subcutaneous routes that seroconverted significantly ( $\geq 4$ fold rise). The vaccine retained a potent titre of $3.1 \log _{10}$ TCID 50 for more than 8 hours after reconstitution in PBS at room temperature. Based on the response of goats to oral vaccination, it is suggested that the vaccine could be administered on the field through the oral routes and has the potential to be adapted to a feedbased administration for wider application to the scattered livestock populations under the extensive system of management.

\section{KEYWORDS}

\section{Thermostable PPR Vaccine; Sheep; Goats; Virus Neutralisation Test; Nigeria}

\section{Introduction}

Peste des petits ruminants (PPR) epidemics can cause mortality rates of $50 \%-80 \%$ in nonimmunized sheep and goat populations [1,2]. Due to the confusion with other diseases, the economic impacts of PPR are probably underestimated. But it is believed that PPR is one of the major constraints to successful small ruminant farming in the tropics $[3,4]$. As with most developing countries where the application of the stamping out policy of eradication is not feasible, the control of PPR has relied on preventive immunoprophylaxis using live attenuated tissue culture Rinderpest vaccine (TCRV) and recently

${ }^{*}$ Corresponding author. employing the use of homologous live attenuated PPR vaccine [5] along with restriction of animal movement and other biosecurity measures. A lot of researches have been carried out on how to prevent and control PPR. These include the use of immune serum [6], formalinised or lapinised Rinderpest virus [7,8], tissue culture Rinderpest vaccine (TCRV) [9], homologous PPR vaccine [10], virus-vectored PPR vaccine [11] and recombinant PPR-Canine adenovirus vaccine [12]. So far, the homologous PPR vaccine has proved to be safer and provides long immunity so that revaccination will not be necessary [13]. In spite of rigorous vaccination programmes, outbreaks of PPR continued to be reported among both vaccinated and nonvaccinated small ruminant popula- 
tions. These outbreaks are attributed largely to such factors like lack of maintenance of cold-chain and faulty administration and handling of the vaccines among others. Developing countries like Nigeria with extreme climatic conditions depend essentially on maintenance of cold-chain to prevent the vaccines from deterioration and loss of efficacy as a result of high ambient temperature. In order to prevent vaccine deterioration and overcome the difficulty of maintaining cold-chain, a thermostable PPR vaccine was developed [14] from the existing thermolabile attenuated variety. In this study, we carried out a field trial of the candidate thermostable PPR vaccine to determine its efficacy when administered to small ruminants in semi-arid zone in north-eastern Nigeria.

\section{Materials and Methods}

\subsection{Vaccine}

A candidate thermostable PPR vaccine developed and described by [14] was used in this study. The vaccine was developed in an excipient consisting of $40 \%$ trehalose and lyophilised using the rapid system of lyophilisation without sublimation as previously described by [15] and modified by [14]. This was followed by the determination of the thermostability at $45^{\circ} \mathrm{C}$ and Residual Moisture level of the candidate PPR vaccine. The vaccine was stored at ambient temperature from the time of production until used.

\subsection{Determination of Potency/Shelf Life of Reconstituted Thermostable Vaccine}

In order to determine the viability and shelf life of the reconstituted vaccine in PBS, the potency of the reconstituted vaccine was determined hourly over a period of 24 hours at room temperature.

\subsection{Field Trial of the Thermostable PPR Vaccine}

Experimental animals

One hundred Sahel goats and 20 sheep were randomly selected from the flocks on the University of Maiduguri Teaching and Research Farms, Maiduguri, Nigeria. The selected animals were tagged with identification numbers and the biodata of each animal including sex and age were taken. The goats were randomly divided into 10 groups (A -to- J) of 10 goats each while the sheep were divided into 4 groups (A -to- E) of 5 sheep each. With the exception of goats in groups $F$ and $G$, members of other groups were dewormed with antihelminthic (Albendazole $\left.{ }^{(\mathrm{R})}\right)$. The rectal temperature of each animal was taken and recorded before and after vaccination. The group distribution of experimental goats and sheep is presented in Table 1.

Vaccination of experimental animals

Each animal was vaccinated with $10^{3} \mathrm{TCID}_{50}$ of the thermostable PPR vaccine. Some vials of the vaccine were diluted with $25 \mathrm{ml}$ and others with $50 \mathrm{ml}$ of sterile PBS. Each animal, with the exception of the control and incontact, were vaccinated with $1 \mathrm{ml}$ of $10^{-3} \mathrm{TCID}_{50} / \mathrm{ml}$ of the reconstituted vaccine. Each group was housed separately and in-contacts were introduced into the corresponding groups. The rectal temperature of each animal in all the groups was taken every other day and the animals were monitored for possible clinical manifestations. All experimental animals were bled on day 21 post vaccination for serum.

\subsection{Virus Neutralization Tests}

Virus neutralization (VN) test was used to detect PPR virus antibody in sera collected from the experimental animals. The test was carried out according to the protocol described by [16]. The highest dilution of serum showing complete inhibition of cytopathic effects was taken as the endpoint antibody titre.

\subsection{Statistical Analysis}

The Geometric mean titres (GMT) of PPR virus neutralising antibody was calculated using the formula described in "Descriptive Statistics" [17]. The GMT was calculated using the formula $\mathrm{X}_{\mathrm{goe}}=\operatorname{antilog}_{10}\left(1 / \mathrm{n} \sum \mathrm{f}_{\mathrm{i}} \log _{10} \mathrm{X}_{\mathrm{i}}\right)$

Table 1. Distribution of experimental animals to different groups.

\begin{tabular}{|c|c|c|c|}
\hline \multicolumn{2}{|r|}{ GOATS } & \multicolumn{2}{|r|}{ SHEEP } \\
\hline Group & Route Of Vaccine Administration & Group & Route Of Vaccine Administration \\
\hline A & Subcutaneous $(\mathrm{S} / \mathrm{C})$ & A & $\mathrm{P} / \mathrm{O}$ \\
\hline $\mathrm{B}$ & Intraocular (I/O) & $\mathrm{B}$ & $\mathrm{I} / \mathrm{N}$ \\
\hline $\mathrm{C}$ & Intranasal (I/N) & $\mathrm{C}$ & $\mathrm{S} / \mathrm{C}$ \\
\hline $\mathrm{D}^{*}$ & Per Os $(\mathrm{P} / \mathrm{O})$ & $\mathrm{D}$ & $\mathrm{I} / \mathrm{M}$ \\
\hline $\mathrm{E}^{\#}$ & Intramuscular (I/M) & & \\
\hline $\mathrm{F}^{\S}$ & Per Os (P/O) undewormed & & \\
\hline G & Unvaccinated undewormed & & \\
\hline $\mathrm{H}$ & In-contact of S/C & & \\
\hline I & In-contact of $\mathrm{P} / \mathrm{O}$ & & \\
\hline $\mathrm{J}$ & In-contact of $\mathrm{I} / \mathrm{N}$ & & \\
\hline
\end{tabular}


where $\mathrm{f}_{\mathrm{i}}=$ frequency and $\mathrm{X}_{\mathrm{i}}=$ reciprocal of dilution. The GMT is the appropriate estimate of central density in dilution assays since each individual observation is represented. Four fold or greater rise in antibody titre is significant.

\section{Results}

Following reconstitution of the vaccine in PBS, it remained viable at room temperature over a considerable period of time. The reconstituted vaccine maintained a titre of $10^{3.1} \mathrm{TCID}_{50}$ for more than 8 hours but dropped significantly after 15 hours at room temperature (Table 2). The small ruminants vaccinated with the candidate thermostable PPR vaccine seroconverted to varying antibody titres depending on the route of inoculation and species of animal involved. The vaccine elicited high level of seroconversion (100\%) in goats and the degree of seroconversion was significantly higher when the vaccine is administered through the intramuscular route (134-fold rise) when compared with other routes of inoculation (Table 3). Table 3 shows the GMT of PPR neutralising antibody detected in goats vaccinated with the thermostable PPR vaccine. All goats vaccinated through the intramuscular ( $/ / \mathrm{M})$, subcutaneous $(\mathrm{S} / \mathrm{C})$, intranasal $(\mathrm{I} / \mathrm{N})$ or per os (P/O) routes significantly seroconverted to a four-fold or more rise (8 - 134 folds) in GMT of neu trail- sing antibody against PPR virus. However, apart from goats that were in-contact to the group inoculated intranasally (that had GMT of reciprocal of PPR virus neutralising antibody of 11), significant seroconversion was not observed among the in-contact animals (Table 4) and only animals vaccinated through the $\mathrm{I} / \mathrm{M}$ and $\mathrm{S} / \mathrm{C}$ routes seroconverted significantly among sheep (Table 5). The highest GMT of PPR neutralising antibodies of 54 and 11.5 were observed in the groups of sheep that were vaccinated through the S/C and I/M route s respectively (Table 5). There were no specific clinical signs or noticeable side effects exhibited by the experimental animals following vaccination with the thermostable PPR vaccine. The rectal temperature of the vaccinated animals remained within the normal range $\left(37.2^{\circ} \mathrm{C}-39.5^{\circ} \mathrm{C}\right)$ throughout the period of experiment. When two animals from each of the vaccinated groups and control group were experimentally challenged with $10^{3} \mathrm{TCID}_{50}$ of virulent PPR virus, all the vaccinated animals were protected and had rapid anamnestic response by seroconverting to varying degrees of PPR neutralising antibodies (Table 6). However, animals in the control group succumbed to experimental challenge with the virulent PPR virus. Besides, there was significant difference between the groups that were dewormed before vaccination and those that were not dewormed.

Table 2. Viability of the thermostable PPR vaccine after reconstitution at different periods.

\begin{tabular}{ccccccccc}
\hline & \multicolumn{7}{c}{ Time (hours) post-reconstitution of vaccine } \\
\cline { 2 - 8 } & 0 & 3 & 8 & 11 & 15 & 20 & 24 \\
\hline Virus titre $\left(\log _{10} \mathrm{TCID}_{50} / \mathrm{ml}\right)$ & $10^{4.5}$ & $10^{4.2}$ & $10^{3.9}$ & $10^{3.1}$ & $10^{2.3}$ & $10^{1.8}$ & $10^{1.2}$ & $10^{0.9}$ \\
Loss in titre & 0 & 0.3 & 0.6 & 1.4 & 2.2 & 2.7 & 3.3 & 3.6 \\
\hline
\end{tabular}

Table 3. Pattern of Geometric Mean (GM) of reciprocal of neutralising antibody (NA) titre in goats vaccinated with thermostable PPR vaccine using different routes of administration.

\begin{tabular}{ccccc}
\hline \multirow{2}{*}{ Group } & \multirow{2}{*}{ Route of vaccine administration } & \multicolumn{1}{c}{ GMT of reciprocal NA titre (days post vaccination) } & \multirow{2}{*}{ Rise in GM of NA titre (Folds) } \\
\cline { 3 - 4 } & & (Day 0) & 453 & 10 \\
$\mathrm{~A}$ & $\mathrm{~S} / \mathrm{C}$ & 44 & 297 & 4.5 \\
$\mathrm{~B}$ & $\mathrm{I} / \mathrm{O}$ & 67 & 237 & 40 \\
$\mathrm{C}$ & $\mathrm{I} / \mathrm{N}$ & 6 & 226 & 8 \\
$\mathrm{D}$ & $\mathrm{P} / \mathrm{O}$ & 51 & 844 & 134 \\
$\mathrm{E}$ & $\mathrm{I} / \mathrm{M}$ & 6 & 970 & 30 \\
$\mathrm{~F}^{\S}$ & $\mathrm{P} / \mathrm{O}$ & 32 & 452.5 & 2.8 \\
$\mathrm{G}^{\#}$ & $\mathrm{~S} / \mathrm{C}$ & 160 &
\end{tabular}

A-E = Vaccinated and dewormed; $\mathrm{F}^{\S}=$ Vaccinated but not dewormed; $\mathrm{G}^{\#}=$ Unvaccinated and not dewormed; S/C = Subcutaneous; $\mathrm{I} / \mathrm{O}=\mathrm{Intraocular}$; $/ \mathrm{N}=$ Intranasal; P/O = Per Os; I/M = Intramuscular; * = Groups that seroconverted to 4 fold or more rise in GM of NA titres is significant.

Table 4. Pattern of Geometric Mean of reciprocal of neutralising antibody titre of in-contact goats of thermostable PPR vaccinated goats (using different routes).

\begin{tabular}{cccc}
\hline \multirow{2}{*}{ Group } & Route of inoculation & GMT of reciprocal of NA titre (day post vaccination/introduction) & Rise in GM of NA titre (Folds)* \\
\cline { 3 - 4 } & & (Day 0) & 231 \\
H & In-contact S/C & 211 & 352 \\
$\mathrm{I}$ & In-contact P/O & 201 & 205 \\
\hline
\end{tabular}

$\mathrm{S} / \mathrm{C}=$ Subcutaneous; $\mathrm{I} / \mathrm{N}=$ Intranasal; P/O = Per Os. * = Groups that seroconverted to 4 fold or more rise in GM of NA titres is significant. 
Table 5. Pattern Geometric Mean (GM) of reciprocal of neutralising antibody (NA) titre in sheep vaccinated with thermostable PPR vaccine using different routes of administration.

\begin{tabular}{ccccc}
\hline \multirow{2}{*}{ Group } & \multirow{2}{*}{ Route of inoculation } & \multicolumn{2}{c}{ GMT of reciprocal of NA titre (day post vaccination) } & \multirow{2}{*}{ Rise in GM of NA titre (Folds)* } \\
\cline { 3 - 4 } & & (Day 0) & $21)$ & 3.5 \\
$\mathrm{~A}$ & $\mathrm{P} / \mathrm{O}$ & 8 & 16 & 2 \\
$\mathrm{~B}$ & $\mathrm{I} / \mathrm{N}$ & 27 & 1470 & 54 \\
$\mathrm{C}$ & $\mathrm{S} / \mathrm{C}$ & 12 & 133 & 11.5 \\
$\mathrm{D}$ & $\mathrm{I} / \mathrm{M}$ & & & \\
\hline
\end{tabular}

$\mathrm{S} / \mathrm{C}=$ Subcutaneous; $\mathrm{I} / \mathrm{N}=$ Intra nasal; P/O = Per Os; I/M = Intra muscular; * = Groups that seroconverted to 4 fold or more rise in GM of NA titres is significant.

Table 6. Response of vaccinated goats to experimental challenge with virulent PPR virus.

\begin{tabular}{ccc}
\hline \multirow{2}{*}{ Routes of vaccination } & Neutralising antibody titre in vaccinated goats challenged with virulent PPR virus (day post challenge) \\
\cline { 2 - 3 } & $\begin{array}{c}\text { (Day 0) } \\
\text { Pre-challenge }\end{array}$ & $\begin{array}{c}\text { (Day 21) } \\
\text { Post-challenge }\end{array}$ \\
\hline \multirow{2}{*}{ Subcutaneous } & $1: 160$ & $1: 640$ \\
& $1: 80$ & $1: 640$ \\
Intra muscular & $1: 320$ & $1: 1280$ \\
& $1: 640$ & $1: 640$ \\
Oral & $1: 10$ & $1: 320$ \\
& $1: 80$ & $1: 160$ \\
Intra nasal & $1: 80$ & $1: 640$ \\
& $1: 20$ & $1: 320$ \\
Intra ocular & $1: 80$ & $1: 160$ \\
\end{tabular}

\section{Discussion}

Field trial of a candidate thermostable PPR vaccine was carried out among goats and sheep managed under extensive system of management. The thermostable PPR vaccine elicited significant seroconversion equal to or more than four-fold rise in neutralising antibody titres among the vaccinated animals using different routes of inoculation. The high level of seroconversion observed among the vaccinees is an indication that the thermostable vaccine produced is immunogenic and efficacious. The vaccine remained viable for more than 8 hours after reconstitution which makes it useful for administration in the field. The response of vaccinated goats is consistent with what was observed with vaccination of goats with homologous PPR vaccine [13] and chimeric PPR vaccine [18]. No specific clinical signs or side effects were observed in all the animals vaccinated with the thermostable PPR vaccine. This is an indication of the safety of the vaccine for use in small ruminants. However, the vaccine failed to be transmitted to in-contact animals (goats) in all the groups except for the intranasally inoculated group that showed significant seroconvertion (11-fold rise in neutralising PPR antibody titre). This is an indication that the thermostable PPR vaccine is poorly transmitted between those vaccinated and in-contact animals. A similar observation was made with thermostable rinderpest vaccine [19]. The seroconversion demonstrated among the in-contact to the intranasal route could be attributed to the route of inoculation which allowed for sufficient vaccine virus replication at the upper respiratory tract and hence ensured rapid spread of high concentration of the virus by aerosol route. The oral and respiratory routes are the main routes of transmission of PPR virus via the oral, nasal and ocular discharges [20]. When comparing the response of the vaccinated animals to the different routes of vaccine administration, the least response was observed in the group vaccinated intraocularly. No plausible explanation could be provided for this finding as it is contrary to the fact that the virus is mainly transmitted through oral, nasal and ocular routes [20]. Based on the responses of the goats vaccinated through different routes with the thermostable PPR vaccine, it is possible for the vaccine to be administered in the field through the oral routes and reduce the stress and trauma of using needle and syringe to administer the vaccine. Besides, there is the potential for the vaccine to be adapted to a feed-based administration for wider application to the scattered livestock populations under the extensive system of management. The sheep only exhibited a significant seroconversion to the thermostable PPR vaccine through the intramuscular and subcutaneous routes. Despite the low seroconversion in some of the vaccinated animals, they all resisted experimental challenge with a virulent PPR virus. The immune protection could be due to cell mediated immune response. All the vaccinated animals exhibited anamnestic immune response following challenge. The performance of the thermostable vaccine following 
reconstitution in PBS is quite interesting, because the titre of the reconstituted vaccine remained well above the OIE recommended dose $\left(10^{2.5} \mathrm{TCID}_{50}\right)$ for more than 8 hours at ambient temperature. No loss in vaccine titre was noticed in this study, which is in contrast to the observations of Sarkar et al. [21] who reported an immediate loss of 0.14 and $0.8 \log _{10} \mathrm{TCID}_{50}$ with the vaccine reconstituted in $\mathrm{MgSO}_{4}$ and $\mathrm{NaCl}$ respectively. The results of the present study suggest that the thermostable vaccine when reconstituted with PBS can be used on the field for up to 8 hours after reconstitution. Although it is always better to reconstitute few vaccine vials at a time when using it on the field.

\section{Conclusion}

The study has revealed that the candidate thermostable PPR vaccine is potent and efficacious when administered to goats through various routes and few routes in sheep. The vaccine elicited protective immune response in vaccinated goats and vaccinated animals resisted challenge to experimental infection with virulent PPR virus. The vaccine is safe and well-tolerated, and no clinical reaction/side effect was observed in vaccinated animals. The vaccine could be administered through the oral route and has potentials to be adapted to locally available small ruminant feed and administered in the form of feed-based vaccine.

\section{Acknowledgement}

This report is part of a study supported by Raw Materials Research and Development Council, Federal Ministry of Science and Technology Abuja, Nigeria, Project number RMRDC/AF/36/SEC/XVII/2994. The authors acknowledge with thanks the cooperation and support of the Management of LANAVET Garoua Cameroun and the University of Maiduguri Teaching and Research Farms, Nigeria for the permission to use their laboratory space and animals respectively. The technical assistance of Elhaj Hamet Moussa of LANAVET Garoua is highly appreciated.

\section{REFERENCES}

[1] M. P. Siddique, M. B. Rahman, S. M. Z. H. Chowdhury, M. A. Kafi and M. S. Alam, "Determination of Efficacy of Thermostable ppr Live Homologous Vaccine Incubated at Room Temperature for 14 Days,” Bangladash Journal of Veterinary Medicine, Vol. 4, No.1, 2006, pp. 43-46.

[2] M. Munir, S. Zohari and M. Berg, "Pathophysiology and Clinical Assessment of Peste des Petits Ruminants," In: Munir et al., Ed., Molecular Biology and Pathogenesis of Peste des Petits Ruminants Virus. A Springer Briefs in Animal Sciences Pub., New York, 2013, pp. 33-47. http://dx.doi.org/10.1007/978-3-642-31451-3_3

[3] A. D. El-Yuguda, L. M. Chabiri, F. Adamu and S. S. Baba, "Peste des petits ruminants Virus (PPRV) Infection among Small Ruminants Slaughtered at the Central Abattoir, Maiduguri, Nigeria,” Sahel Journal of Veterinary Science, Vol. 8, No. 2, 2009, pp. 93-96.

[4] A. Sen, P. Saravanan, V. Balamurugan, K. K. Rajak, S. B. Sudhakar, V. Bhanuprakash, S. Parida and R. K. Singh, "Vaccines against Peste des petits ruminants Virus," Expert Review of Vaccines, Vol. 9, No. 7, 2010, pp. 785-796. http://dx.doi.org/10.1586/erv.10.74

[5] A. D. El-Yuguda, D. N. Bukbuk and A. Andrew, "Response of Sahel Goats tp Homologous PPR Vaccine (Capripestovax $^{\mathrm{R}}$ ) under Field Conditions in Maiduguri, Nigeria,” Tropical Veterinarian, Vol. 29, No. 4, 2011, pp. 2126.

[6] F. D. Adu and T. E. Joannis, "Serum-Virus Simultaneous Method of Immunization against PPR,” Tropical Animal Health and Production, Vol. 16, No. 2, 1984, pp. 119-122. http://dx.doi.org/10.1007/BF02239856

[7] L. Gargadenne and A. Lalanne, "La Peste des Petits Ruminanats” Bulletin des Services Zootechniques et des Epizooties de l'Afrique Occidentale Française, Vol. 5, No. 1, 1942, pp. 16-21.

[8] P. Mornet, J. Orue, Y. Gilbert, G. Thiery and M. Sow, "La peste des petits ruminants en Afrique Occidentale Francaise: Ses Rapports Avec la Peste Bovine," Revue d'Élevage et de Médecine Vétérinaire des Pays Tropicaux, Vol. 9, 1956, pp. 313-335.

[9] C. A. Mebus and M. C. Van den Ende, "The Use of Thermostable Vero Cell-Adapted Rinderpest Vaccine as a Heterologous Vaccine against Peste des petits ruminants," Researches in Veterinary Science, Vol. 54, No. 2, 1990, pp. 212-216.

[10] A. Diallo, T. Barrett, M. Barbron, M. S. Shaila and W. P. Taylor, "Differentiation of Rinderpest and Peste des petits ruminants Viruses Using Specific cDNA Clones,” Journal of Virological Methods, Vol. 23, No. 2, 1989, pp. 127-136.

[11] W. Chen, S. Hu, L. Qu, Q. Hu, Q. Zhang, H. Zhi, K. Huang and Z. Bu, “A Goat Poxvirus-Vectored Peste-DesPetits-Ruminants Vaccine Induces Long-Lasting Neutralization Antibody to High Levels in Goats and Sheep," Vaccine, Vol. 28, No. 30, 2010, pp. 4742-4750. http://www.ncbi.nlm.nih.gov/pubmed20471441 http://dx.doi.org/10.1016/0166-0934(89)90126-2

[12] J. Qin, H. Huang, Y. Ruan, X. Hou, S. Yang, C. Wang, G. Huang, T. Wang, N. Feng, Y. Gao and X. Xia, “A Novel Recombinant Peste des petits ruminants-Canine Adenovirus Vaccine Elicits Long-Lasting Neutralizing Antibody Response against PPR in Goats,” PLoS One, Vol. 7, No. 5, 2012, p. E37170. http://www.ncbi.nlm.nih.gov/pubmed22623990

[13] D. N. Awa, A. Ngagnou, E. Tefiang, D. Yaya and A. Njoya, "Post Vaccination Colostral Peste des petits ruminants Antibody Dynamics in Research Flocks of Kirdi Goats and Foulbe Sheep of North Cameron,” Preventive Veterinary Medicine, Vol. 5, 2002, pp. 267-271.

[14] S. S. Baba, A. D. El-Yuguda, G. O. Egwu, A. Y. Ribadu, 
A. G. Ambali, M. D. Abubakar, U. I. Ibrahim and N. Zoyem, "Development and Evaluation of the Efficacy of Heat Tolerant Peste des petits ruminants (PPR) Vaccine in Nigeria," Proceedings of International Conference on Adaptive Science \& Technology (ICAST), Accra, Ghana, 2007, pp. 129-132

[15] E. E., Worrall, J. K. Litamoi, B. M. Seck and G. Ayelet, "Xerovac: An Ultra Rapid Method for the Dehydration and Preservation of Live Attenuated Rinderpest and Peste des petits ruminants Vaccines," Vaccine, Vol. 19, No. 7-8, 2001, pp. 834-839.

[16] A. D. El-Yuguda, S. S. Baba, A. G. Ambali and G. O. Egwu, "Seroprevalence of Peste des petits ruminants among Domestic Small and Large Ruminants in the Semi-Arid Region of North-Eastern Nigeria," Veterinary World, Vol. 6, No. 10, 2013, pp. 807-811. http://www.veterinaryworld.org/Vol.6/Oct-2013/23.pdf

[17] CDC (Centre for disease control), "Descriptive Statistics: Measure of Central Tendency and Dispersion,” Centre for Disease Control and Prevention Atlanta Georgia USA, 1988.

[18] S. C. Das, M. D. Baron, M. A. Skinner and T. Barrett, "Improved Technique for Transient Expression and Nega- tive Strand Virus Rescue Using Fowl Pox T7 Recombinant Virus in Mammalian Cells,” Journal of Virological Methods, Vol. 89, No. 1-2, 2000, pp. 119-127. http://dx.doi.org/10.1016/S0166-0934(00)00210-X

[19] J. C. Mariner, J. A. House, C. A. Mebus and M. C. Van den Ende, “The Use of Thermostable Vero Cell-Adapted Rinderpest Vaccine as a Heterologous Vaccine against Peste des petits ruminants," Research in Veterinary Science, Vol. 54, No. 2, 1990, pp. 212-216. http://dx.doi.org/10.1016/0034-5288(93)90059-O

[20] E. Couacy-hymann, S. C. Bodjo, T. Danho, M. Y. Koffi, G. Libeau and A. Diallo, "Early Detection of Viral Excretion from Experimentally Infected Goats with Pets des Petits Ruminants Virus,” Preventive Veterinary Medicine, Vol. 78, No. 1, 2007, pp. 85-88. http://dx.doi.org/10.1016/j.prevetmed.2006.09.003

[21] J. Sarkar, B. P. Sreenivasa, R. P. Singh, P. Dhar and S. K. Bandyopadhyay, "Comparative Efficacy of Various Chemical Stabilizers on the Thermostability of a Live Attenuated Peste des petits ruminants (PPR) Vaccine," Vaccine, Vol. 21, No. 32, 2003, pp. 4728-4735. http://dx.doi.org/10.1016/S0264-410X(03)00512-7 